\title{
Psikoedukasi "Temanku Istimewa" terhadap Peer acceptance Siswa Reguler di Sekolah Dasar Inklusi
}

\author{
Wenny Hikmah Syahputri ${ }^{\left.1^{*}\right)}$, Neneng Tati Sumiati ${ }^{2}$ \\ 1*) Fakultas Psikologi Universitas Mercu Buana Jakarta \\ ${ }^{2}$ Universitas Islam Negeri Syarif Hidayatullah Jakarta \\ e-mail*) : wennyhikmah@gmail.com
}

\begin{abstract}
Sekolah yang belum menerima siswa berkebutuhan khusus, berpotensi mempengaruhi perkembangan proses belajar mereka di sekolah inklusi. Bentuk hubungan dengan teman sebaya adalah penerimaan individu di dalam kelompok teman sebayanya (peer accepatance). Maka, perlunya metode psikoedukasi untuk memberikan pengetahuan keistimewaan siswa berkebutuhan khusus sehingga meningkatkan peer acceptance siswa terhadap siswa berkebutuhan khusus. Populasi dalam penelitian ini adalah siswa-siswi yang bersekolah di SD Negeri 05 Kembangan Jakarta Barat. Teknik pengambilan sampel yang digunakan adalah nonprobability sampling dengan teknik convenience sampling. Sampel yang digunakan dalam penelitian sebanyak 78 siswa, yang terdiri dari kelas 2, 3, 4, 5, dan 6, namun yang mengikuti hingga tuntas (mengikuti kegiatan penelitian sampai post test) sebanyak 69 orang. Penelitian bertujuan mengetahui pengaruh dari psikoedukasi dengan tema Temanku Istimewa terhadap peer acceptance siswa reguler di sekolah Inklusi. Penelitian ini membandingkan rata-rata peer acceptance sebelum dan sesudah perlakukan. Hasil penelitian memperlihatkan bahwa psikoedukasi temanku istimewa secara signifikan efektif meningkatkan peer acceptance siswa regular terhadap siswa berkebutuhan khusus dengan down syndrome, autis, dan tuna rungu. Namun, siswa yang mengalami lambat belajar psikoedukasi temanku istimewa menunjukkan peningkatan peer acceptance siswa regular, tetapi perubahannya tidak signifikan. Hasil analisis menggunakan MANOVA terlihat bahwa tingkat kelas dan jenis kelamin tidak mempengaruhi peer acceptance. Tingkat kelas hanya berpengaruh pada post-test peer acceptance terhadap tunarungu ( $p=0.04$ kurang dari 0.05).
\end{abstract}

Keywords: Peer acceptance, Psikoedukasi, siswa Inklusi

\begin{abstract}
Abstrak. Schools that have not accepted students with special needs have the potential to affect the development of their learning process in inclusive schools. The form of relationship with peers is the acceptance of the individual in the peer group (peer acceleration). So, the need for psychoeducation methods to provide knowledge of the privileges of students with special needs so as to increase student peer acceptance of students with special needs. The population in this study were students who attended SD Negeri 05 Kembangan, West Jakarta. The sampling technique used was nonprobability sampling with convenience sampling technique. The sample used in the study was 78 students, consisting of level 2, 3, 4, 5, and 6, but those who followed it to completion (following research activities to post test) were 69 people. This study aims to determine the effect of psychoeducation with the theme "Temanku Istimewa" on peer acceptance of regular students in inclusive schools. This study compares the average peer acceptance before and after treatment. The results showed that Pyschoeducation theme "Temanku Istimewa" was significantly effective in increasing peer acceptance of regular students towards students with special needs with Down syndrome, autism, and hearing impairment. However, students who experienced slow learning about "Temanku Istimewa" psychoeducation showed an increase in peer acceptance of regular students, but the change was not significant. The analysis using MANOVA shows that class level and gender do not affect peer acceptance. Class level only affects post-test peer acceptance for deaf people ( $p=0.04$ less than 0.05 ).
\end{abstract}

Kata Kunci: Peer acceptance, Psychieducation, Inclusion student 


\section{Pendahuluan}

Kondisi lingkungan sekolah yang belum sepenuhnya menerima siswa berkebutuhan khusus, berpotensi mempengaruhi perkembangan dan proses belajar siswa berkebutuhan khusus di sekolah inklusi. Perkembangan dan proses belajar selama di sekolah akan banyak dipengaruhi oleh hubungan sosial antara sesama rekan sebaya (Odom, I: Zercher, Marquart \& Brown, 2006). Salah satu bentuk hubungan dengan teman sebaya adalah penerimaan individu di dalam kelompok teman sebayanya atau peer accepatance. Maka dari itu, perlunya suatu metode psikoedukasi yang tepat dalam rangka memberikan pengetahuan terkait keistimewaan siswa berkebutuhan khusus. Sehingga mampu meningkatkan peer acceptance bagi siswa terhadap siswa berkebutuhan khusus.

Melalui pendidikan Inklusi siswa dapat saling belajar di antara mereka sehingga terbentuk iklim interaksi yang kooperatif. Menurut Mangungsong (2011) di dalam interaksi kelompok integrasi, jika kelompok siswa memiliki kecerdasan yang heterogen, maka suasana belajar kooperatif lebih unggul dari pada suasana belajar kompetitif. Sebaliknya, bila kelompok siswa memiliki kecerdasan homogen maka suasana belajar kompetitif lebih unggul dibandingkan suasana belajar kooperatif. Dari berbagai penelitian yang dilakukan Jhonson (dalam Mangungsong, 2011) menyebutkan, bahwa suasana belajar kooperatif adalah manifestasi dari hakikat manusia sebagai makhluk sosial. Keberhasilan dalam meningkatkan sikap positif melalui belajar kooperatif baru dapat berpengaruh positif pada prestasi belajar bila memiliki dua unsur, yaitu adanya imbalan dari kelompok dan peran serta dari individunya (Slavin, dalam Mangungsong 2011).

Pada penelitian yang dilakukan Hasanah (2015) di SMP Inklusi, ia mengukur sikap terhadap 200 siswa reguler terhadap siswa berkebutuhan khusus dan menunjukkan, bahwa adanya hubungan negatif antara sikap siswa reguler terhadap siswa berkebutuhan khusus. Masalah interaksi sosial antara siswa normal dan berkebutuhan khusus di Indonesia, khususnya di Jakarta diperkuat pula dengan hasil penelitian yang dilakukan oleh Rahmayati (2013). Dalam penelitiannya diperoleh bahwa peer acceptance siswa normal terhadap siswa berkebutuhan khusus di SMP Inklusif tergolong rendah.

Perkembangan dan proses belajar selama di sekolah akan banyak dipengaruhi oleh hubungan sosial antara sesama rekan sebaya (Odom, I: Zercher, Marquart \& Brown, 2006). Gest, Graham, Bermann, dan Hartup (dalam Berk, 2007) menjelaskan bahwa anak yang lebih diterima akan memiliki lebih banyak teman dan memiliki hubungan yang positif dengan temannya.

Menurut Ajzen (dalam Losey, 2009) menjelaskan faktor sosial dan kognitif mempengaruhi perilaku yang dipilih seseorang. Psikoedukasi menstimulasi faktor kognitif siswa sehingga akan menentukan sikap yang akan dipilihnya. Pada penelitian Talita, Tanja, Gert, \& Huub (2011) menyebutkan, bahwa observational learning meningkatkan hasil kreativitas khususnya pada domain seni visual. Hasil penelitian ini menguatkan bahwa metode observational learning dapat digunakan untuk mempelajari hal baru baik itu dalam bentuk pengetahuan maupun keterampilan. Penelitian ini bertujuan untuk mengetahui pengaruh dari psikoedukasi yang diberikan tema Temanku Istimewa terhadap peer acceptance siswa reguler di sekolah dasar Inklusi.

\section{Metode}

Variabel penelitian ini adalah Psikoeduksi Temanku Istimewa sebagai independent variable (IV), tingkatan kelas dan jenis kelamin sebagai IV serta peer acceptance sebagai dependent variable (DV). Penelitian bertujuan untuk membuktikan efektivitas psikoedukasi temanku istimewa terhadap penerimaan siswa regular terhadap siswa berkebutuhan khusus SDN Inkulusi Kembangan Jakarta Barat. Pendekatan yang digunakan adalah kuantitatif dengan jenis penelitian comparative dengan desain penelitian eksperimen, yaitu pre-test dan post-test. 
Populasi penelitian ini adalah siswa-siswi di SD Negeri 05 Kembangan Jakarta Barat. Teknik pengambilan sampel nonprobability sampling dengan teknik convenience sampling. Sampel sebanyak 78 siswa, terdiri dari kelas 2 s.d 6, namun yang mengikuti hingga tuntas (mengikuti kegiatan penelitian sampai post test) sebanyak 69 orang.

Pada penelitian ini psikoedukasi diberikan dengan memberikan informasi tentang anak berkebutuhan khusus melalui cerita yang disampaikan oleh seorang pendongeng. Penelitian ini menggunakan modul yang berisi tentang karakteristik dan cara berinteraksi dengan anak berkebutuhan khusus, yaitu anak dengan down syndrome, Autis, ADHD, lambat belajar, dan tuna rungu. Adapun teknik pengumpulan data menggunakan skala. Proses pengisiannya dibantu oleh tim peneliti dengan cara membacakan dan menjelaskan maksud dari setiap soal dalam skala tersebut dan mencatatkan jawaban atau respon dari responden penelitian.

Instrumen yang digunakan terdiri dari skala peer acceptance siswa regular terhadap siswa berkebutuhan kusus. Pada penelitian ini menggunakan Peer acceptance Scale (PAS) yaitu alat ukur yang mengukur peer acceptance yang dikonstruksi oleh Piercy, Wilton, dan Townsend (2002). Pengukuran peer acceptance yang diukur pada PAS terdiri dari lima item dan untuk kepentingan penelitian ini ditambah satu pertanyaan yang terkait dengan pilihan teman istimewa yang ingin di jadikan teman.

Selain itu, penelitian ini juga menggunakan modul yang berisi tentang karakteristik dan cara berinteraksi dengan anak berkebutuhan khusus, yaitu anak dengan down syndrome, Autis, ADHD, lambat belajar, dan tuna rungu. Modul tersebut dikemas dengan bahasa yang mudah dipahami siswasiswi sekolah dasar dan disampaikan oleh pendongeng yang dapat memudahkan siswa-siswi regular memahami materi yang disampaikan.

Penelitian ini membandingkan data pre-test dan post-test tentang peer acceptance siswa regular terhadap siswa dengan down syndrome, autis, ADHD, lambat belajar dan tuna rungu. Dengan demikian, teknik analisis data yang digunakan pada penelitian ini adalah Paired Sample T-Test dan MANOVA dengan bantuan SPSS versi 20.0.

\section{Hasil}

Subjek pada penelitian ini berjumlah 69 orang yang merupakan siswa-siswi mulai dari kelas II hingga kelas VI yang bersekolah di SD Negeri 05 Kembangan. Berdasarkan tabel 1 dapat diketahui dari 69 responden dalam penelitian ini didominasi oleh laki-laki, banyaknya jumlah responden laki-laki adalah sebesar 42 atau 60,9\% sedangkan responden perempuan sebesar 27 atau 39,1\%. Jika dilihat dari persebaran kelas pada penelitian ini jumlah responden terbanyak adalah siswa dari kelas 5 , banyaknya jumlah responden kelas 5 adalah sebesar 24 orang atau 34,8\% sedangkan jumlah responden yang paling sedikit adalah siswa kelas 6, banyaknya jumlah responden kelas 6 adalah sebesar 7 orang atau 10,2\%.

Tabel 1

Gambaran Umum Subjek Penelitian (N=69)

\begin{tabular}{lll}
\hline Deskripsi & Jumlah & Presentase (\%) \\
\hline Jenis Kelamin & & \\
Laki-laki & 42 & 60,9 \\
Perempuan & 27 & 39,1 \\
\hline Kelas & & \\
Kelas 2 & 13 & 18,8 \\
Kelas 3 & 13 & 18,8 \\
Kelas 4 & 12 & 17,4 \\
Kelas 5 & 24 & 34,8 \\
Kelas 6 & 7 & 10,2 \\
\hline
\end{tabular}


Berdasarkan tabel 2 diketahui bahwa jumlah respon adalah sebanyak 69 orang responden. Responden tersebut memiliki skor peer acceptance pada siswa dengan DS, siswa dengan Autis, siswa dengan lambat belajar, dan siswa dengan tuna rungu menunjukkan bahwa skor post-test lebih besar dibanding rata-rata pre-test. Hanya rata-rata pre-test dan post-test peer acceptance sama.

\section{Tabel 2 Analisis Deskriptif}

\begin{tabular}{lllcc}
\hline & Mean & N & Std. Deviation & Std. Error Mean \\
\hline PRE Peer acceptance Down Syndrome & 6.38 & 69 & 2.358 & .284 \\
\hline POST Peer acceptance Down Syndrome & 7.3333 & 69 & 2.31788 & .27904 \\
\hline PRE Peer acceptance Autis & 6.0870 & 69 & 2.62196 & .31565 \\
\hline POST Peer acceptance Autis & 6.9855 & 69 & 2.05436 & .24732 \\
\hline PRE Peer acceptance ADHD & 6.0870 & 69 & 2.48962 & .29972 \\
\hline POST Peer acceptance ADHD & 6.0870 & 69 & 2.76394 & .33274 \\
\hline PRE Peer acceptance Lambat Belajar & 6.8986 & 69 & 2.73939 & .32978 \\
\hline POST Peer acceptance Lambat Belajar & 7.0290 & 69 & 2.43124 & .29269 \\
\hline PRE Peer acceptance Tuna Rungu & 6.2754 & 69 & 2.47864 & .29839 \\
\hline POST Peer acceptance Tuna Rungu & 6.9130 & 69 & 2.44191 & .29397 \\
\hline
\end{tabular}

Analisis data dalam penelitian ini menggunakan analisis Uji Paired Sample T-Test yaitu pengujian yang digunakan untuk membandingkan selisih dua mean dari dua sampel yang berpasangan. Pada penelitian ini, yaitu membandingkan rata-rata peer acceptance sebelum dan sesudah perlakukan. Tabel 3 menunjukkan hasil uji statistik dari uji perbedaan, dimana peer acceptance terhadap siswa dengan DS, siswa dengan Autis, dan siswa dengan tuna rungu menunjukkan perbedaan yang signifikan.

Tabel 3. Hasil Uji Beda Sebelum dan Sesudah Perlakuan

\begin{tabular}{|c|c|c|c|}
\hline & $\mathbf{t}$ & df & Sig \\
\hline PRE Peer acceptance Down Syndrome & \multirow{2}{*}{-2.807} & \multirow{2}{*}{68} & \multirow{2}{*}{$.007^{* *}$} \\
\hline POST Peer acceptance Down Syndrome & & & \\
\hline PRE Peer acceptance Autis & \multirow{2}{*}{-2.546} & \multirow{2}{*}{68} & \multirow{2}{*}{$.013^{*}$} \\
\hline POST Peer acceptance Autis & & & \\
\hline PRE Peer acceptance ADHD & \multirow{2}{*}{.000} & \multirow{2}{*}{68} & \multirow{2}{*}{1.000} \\
\hline POST Peer acceptance ADHD & & & \\
\hline PRE Peer acceptance Lambat Belajar & \multirow{2}{*}{-.370} & \multirow{2}{*}{68} & \multirow{2}{*}{.712} \\
\hline POST Peer acceptance Lambat Belajar & & & \\
\hline PRE Peer acceptance Tuna Rungu & \multirow{2}{*}{-2.201} & \multirow{2}{*}{68} & \multirow{2}{*}{$.031^{*}$} \\
\hline POST Peer acceptance Tuna Rungu & & & \\
\hline
\end{tabular}

$\mathrm{P} \varangle 0.05$

Tabel 4 memperlihatkan hasil uji beda peer acceptance berdasarkan tingkat kelas dan jenis kelamin. Berdasarkan hasil analisis dengan menggunakan MANOVA terlihat bahwa tingkat kelas dan jenis kelamin tidak mempengaruhi peer acceptance baik pada sebelum maupun sesudah perlakuan diberikan. Tingkat kelas hanya berpengaruh pada post-test peer acceptance terhadap tunarungu $(\mathrm{p}=0.04 \varangle 0.05)$.

\section{Pembahasan}

Temuan pada penelitian ini mengungkapkan bahwa psikoedukasi temanku istimewa efektif meningkatkan peer acceptance siswa regular terhadap siswa dengan down syndrome, autis, dan tunarungu. Hal ini sejalan dengan hasil penelitian yang dilakukan oleh Campbell dan Glimore (2003) juga Morton 
dan Campbell (2007) memberikan edukasi pada siswa reguler berdampak pada perilaku yang positif pada anak down syndrome. Perilaku positif juga ditunjukkan oleh siswa reguler dalam menerima anak autis atau HFA (Laws \& Kelly, 2005; Ranson \& Byrne, 2014; Staniland \& Byrne, 2013) juga anak tuna rungu (S. D. Antia et al., 2002).

Tabel 4 Hasil Uji Beda berdasarkan tingkat kelas dan jenis kelamin

\begin{tabular}{|c|c|c|c|c|c|c|}
\hline & & & df & $\mathbf{F}$ & Sig & $\begin{array}{l}\text { Observer } \\
\text { Power }\end{array}$ \\
\hline \multirow{4}{*}{$\begin{array}{l}\text { Peer acceptance pada Down } \\
\text { Syndrome }\end{array}$} & \multirow[t]{2}{*}{ Kelas } & Pre & 4 & 1.779 & .144 & .513 \\
\hline & & Post & 4 & 1.250 & .299 & .369 \\
\hline & \multirow[t]{2}{*}{ Jenis Kelamin } & Pre & 1 & 2.085 & .539 & .094 \\
\hline & & Post & 1 & .529 & .754 & .051 \\
\hline \multirow[t]{4}{*}{ Peer acceptance pada Autis } & \multirow[t]{2}{*}{ Kelas } & Pre & 4 & .298 & .878 & .112 \\
\hline & & Post & 4 & 1.253 & .298 & .570 \\
\hline & \multirow[t]{2}{*}{ Jenis Kelamin } & Pre & 1 & .099 & .754 & .061 \\
\hline & & Post & 1 & .010 & .919 & .051 \\
\hline \multirow[t]{4}{*}{ Peer acceptance pada ADHD } & \multirow[t]{2}{*}{ Kelas } & Pre & 4 & 1.832 & .134 & .527 \\
\hline & & Post & 4 & 1,256 & .297 & .371 \\
\hline & \multirow[t]{2}{*}{ Jenis Kelamin } & Pre & 1 & .279 & .599 & .082 \\
\hline & & Post & 1 & .091 & .764 & .060 \\
\hline \multirow{4}{*}{$\begin{array}{l}\text { Peer acceptance pada Lambat } \\
\text { Belajar }\end{array}$} & \multirow[t]{2}{*}{ Kelas } & Pre & 4 & .859 & .494 & .258 \\
\hline & & Post & 4 & 1.733 & .154 & .501 \\
\hline & \multirow[t]{2}{*}{ Jenis Kelamin } & Pre & 1 & .119 & .731 & .063 \\
\hline & & Post & 1 & .622 & .433 & .121 \\
\hline \multirow{4}{*}{$\begin{array}{l}\text { Peer acceptance pada Tuna } \\
\text { Rungu }\end{array}$} & \multirow[t]{2}{*}{ Kelas } & Pre & 4 & 2.487 & .052 & .676 \\
\hline & & Post & 4 & 2.788 & $.034^{*}$ & .733 \\
\hline & \multirow[t]{2}{*}{ Jenis Kelamin } & Pre & 1 & .003 & .955 & .050 \\
\hline & & Post & 1 & 1.478 & .229 & .224 \\
\hline
\end{tabular}

$\mathrm{P}<0.050$

Adapun bagi siswa dengan ADHD dan siswa yang mengalami lambat belajar, psikoedukasi temanku istimewa tidak berpengaruh pada peer acceptance siswa reguler. Hasil penelitian ini sejalan dengan penelitian yang menunjukkan bahwa anak ADHD tidak disukai oleh siswa normal karena perilaku mereka yang lebih agresif menghambat aspek sosial mereka (Boer \& Pijl, 2016; Mikami et al., 2013; Pelham \& Milich, 1984). Hal ini kemungkinan siswa regular masih belum memahami kondisi dari siswa dengan ADHD dan siswa lambat belajar. Siswa ADHD dan siswa dengan lambat belajar memiliki karakteristik yang berbeda dengan siswa dengan down syndrome, autis dan tunarungu. Pada siswa dengan down syndrome, autis, dan tuna rungu terdapat ciri fisik yang dapat dikenali dengan mudah oleh siswa regular sedangkan siswa dengan ADHD dan lambat belajar sulit dikenali. Siswa dengan ADHD dan lambat belajar secara fisik sama seperti siswa reguler lain pada umumnya. Mereka hanya memiliki kebiasaan dalam berperilaku dan belajar yang berbeda dengan siswa reguler. Penelitian yang dilakukan oleh Putnam et al. (1996) dan Piercy et al. (2002) menggunakan program berbasis cooperative learning dengan jangka waktu yang berbulan-bulan untuk meningkatkan keterbukaan siswa normal terhadap siswa lambat belajar. Tidak hanya itu, Rillota dan Nettelbeck (2007) menerapkan program ADP (awareness of disability training program) di mana siswa normal diajarkan untuk belajar bagaimana menghargai siswa dengan siswa lambat belajar juga ikut terlibat belajar bersama mereka. Sehingga, untuk memahami karakteristik siswa berkebutuhan khusus non-fisik, seperti ADHD dan lambat belajar perlu dilakukan proses yang panjang dan berulang-ulang untuk meningkatkan penerimaan terhadap teman sebaya.

Keterbatasan dalam penelitian ini adalah proses pengambilan data kurang dapat dilakukan sesuai dengan rencana prosedur. Dimana beberapa siswa yang ikut psikoedukasi tidak dapat diikutsertakan 
sebagai sampel penelitian karena tidak mengikuti pretest dan posttest. Penelitian ini dapat dilanjutkan dengan melakukan prosedur yang lebih sistematis alur pengambilan data dan dapat pula diteliti pada lokasi sekolah Inklusi yang berbeda.

\section{Kesimpulan dan Rekomendasi}

Hasil penelitian memperlihatkan bahwa psikoedukasi temanku istimewa secara signifikan efektif meningkatkan peer acceptance siswa regular terhadap siswa berkebutuhan khusus dengan down syndrome, autis, dan tuna rungu. Namun, bagi siswa yang mengalami lambat belajar psikoedukasi temanku istimewa menunjukkan adanya peningkatan peer acceptance siswa regular, tetapi perubahannya tidak signifikan. Adapun bagi siswa dengan ADHD psikoedukasi temanku istimewa tidak menunjukkan adanya peningkatan peer acceptance pada siswa regular. Berdasarkan tingkatan kelas dan jenis kelamin, hasil analisis data mengungkapkan tidak ada pengaruh yang signifikan terhadap peer acceptance, baik sebelum maupun setelah perlakuan, kecuali tingkatan kelas terhadap peer acceptance pada siswa tuna rungu setelah perlakuan.

Penelitian ini terbukti bahwa psikoedukasi temanku istimewa efektif dapat meningkatkan peer acceptance siswa regular terhadap siswa dengan down syndrome, autis, dan tuna rungu. Sedangkan, bagi siswa siswa dengan lambat belajar dan ADHD pengaruh psikoedukasi temanku istimewa tidak berpengaruh terhadap peer acceptance siswa regular. Sehingga penelitian berikutnya disarankan menggunakan dengan desain time series.

Salah satu aspek dalam psikoedukasi temanku istimewa adalah cara berinteraksi dengan siswa berkebutuhan khusus sehingga untuk meningkatkan peer acceptance siswa regular cara berinteraksi perlu dilatihkan agar dapat meningkatkan keterampilan interaksi sosial siswa regular terhadap siswa berkebutuhan khusus sehingga baik siswa regular maupun siswa berkebutuhan khusus dapat berinteraksi secara natural.

\section{Daftar Pustaka}

Adibsereshki, N., \& Salehpour, Y. (2016). Peer acceptance of Students with and Without Inclusion Experience towards Students with Special Needs in Unisex Schools of Tehran. Eductation, 3(13), 575-588. https://doi.org/10.1080/03004279.2012.745890

André, A., Deneuve, P., \& Louvet, B. (2011). Cooperative learning in physical education and acceptance of students with learning disabilities. Journal of Applied Sport Psychology, 23(4), 474-485. https://doi.org/10.1080/10413200.2011.580826

Antia, S. D., Stinson, M. S., \& Gaustad, M. G. (2002). Developing Membership in the Education of Deaf and Hardof- Hearing Students in Inclusive Settings. Journal of Deaf Studies and Deaf Education, 7(3), 214-229.

Antia, S., \& Kreimeyer, K. H. (1996). Social Interaction and Acceptance of Deaf or Hard-of-Hearing Children and Their Peers: A Comparison of Social-Skills and Familiarity-Based Interventions. The Volta, 98(4), 1-7.

Avramidis, E. (2013). Self-Concept, Social Position and Social Participation of Pupils with SEN in Mainstream Primary Schools. Research Papers in Education, 28(4), 421-442. https://doi.org/10.1080/02671522.2012.673006

Bakker, J. T. A., \& Bosman, A. M. T. (2003). Self-image and peer acceptance of Dutch students in regular and special education. Learning Disability Quarterly, 26(1), 5-14.

Boer, A. De, \& Pijl, S. J. (2016). The acceptance and rejection of peers with ADHD and ASD in general secondary education. The Journal of Educational Research, 109(3), 352-332. https://doi.org/10.1080/00220671.2014.958812

Campbell, J., \& Gilmore, L. (2003). Changing student teachers ' attitudes towards disability and inclusion. Journal of 
Intellectual \& Developmental Disability, 28(4), 369-379. https://doi.org/10.1080/13668250310001616407

Cook, B. G., \& Semmel, M. I. (1999). Acceptance of Included Students with Disabilities as a Function of Severity of Disability and Classroom Composition. The Journal of Special Education, 33(1), 50-61.

Correa-torres, S. M. (2008). The Nature of the Social Experiences of Students with Deaf-Blindness Who Are Educated in Inclusive Settings. Journal of Visual Impairment $\mathcal{E}$ Blindness, 102(5), 272-283. https://doi.org/10.1177/0145482X008102000503

David, R., \& Kuyina, A. B. (2012). Social Inclusion: Teachers As Facilitators In Peer acceptance Of Students With Disabilities In Regular Classrooms In Tamil Nadu, India. International Journal of Special Education, 27(2), 157168.

Diamond, K. E., \& Hestenes, L. L. (1996). Preschool Children' s Conceptions of Disabilities: The Salience of Disability in Children's Ideas About Others. Topics in Early Childhood Special Education, 16(4), 458-475. https://doi.org/https://doi.org/10.1177/027112149601600406

Edwards, B. M., Cameron, D., King, G., Mcpherson, A. C., Edwards, B. M., Cameron, D., ... King, G. (2019). How Students without Special Needs Perceive Social Inclusion of Children with Physical Impairments in Mainstream Schools: A Scoping Review How Students without Special Needs Perceive Social Inclusion of Children with Physical Impairments in. International Journal of Disability, Development and Education, 00(00), 127. https://doi.org/10.1080/1034912X.2019.1585523

Frostad, P., \& Pijl, S. J. (2007). Does Being Friendly Help In Making Friends? The Relation Between The Social Position And Social Skills Of Pupils With Special Needs In Mainstream Education. European Journal of Special Needs Education, 22(1), 15-30. https://doi.org/10.1080/08856250601082224

Gardiner, E., \& Iarocci, G. (2014). Students with Autism Spectrum Disorder in the University Context: Peer acceptance Predicts Intention to Volunteer. Journal Autism Development Disorder, 44(2014), 1008-1017. https://doi.org/10.1007/s10803-013-1950-4

Gresham, F. M., \& MacMillan, D. L. (1997). Social competence and affective characteristics of students with mild disabilities. Review of Educational Research, 67(4), 377-415. https://doi.org/10.3102/00346543067004377

Hartup, W. W., \& Moore, S. G. (1990). Early Peer Relations: Developmental Significance and Prognostic Implications. Early Childhood Research Quarterly, 5(1), 1-17.

Hendrickson, J. M., Shokoohi-yekta, M., Hamre-nietupski, S., \& Gable, R. A. (1996). Students ' Perceptions on Being Friends with Peers with Severe. Exceptional Children, 63(1), 19-28.

Hunt, P., Farron-davis, F., Beckstead, S., Curtis, D., \& Goetz, L. (1994). Evaluating the Effects of Placement of Students with Severe Disabilities in General Education Versus Special Classes. JASH, 19(3), 200-214.

Hvizdos, M. A. (1980). Acceptance-Rejection of Children with Special Needs in Mainstreamed Preschools. University Pittsburgh.

Kemple, K., Duncan, T. K., \& Strangis, D. (2002). Supporting young children 's peer competence in an era of inclusion. Childhood Education, 79(1), 40-47.

Laws, G., \& Kelly, E. (2005). The attitudes and friendship intentions of children in United Kingdom mainstream schools towards peers with physical or intellectual disabilities. International Journal of Disability, Development and Education, 52(2), 37-41. https://doi.org/10.1080/10349120500086298

Lopez-Willliam, A., Chacko, A., Wymbs, B. T., Fabiano, G. A., Seymour, K. E., Gnagy, E. M., ... Morris, T. L. (2005). Athletic Performance and Social Behavior as Predictors of Peer acceptance in Children Diagnosed With Attenttion-Deficit/Hyperactivity Disorder. Emotional and Behavioral Disorder, 13(3), 173-180.

Maras, P., \& Brown, R. (2000). Effects of Different Forms of School Contact on Children's Attitudes toward Disabled and Non-disabled Peers. British Journal of Educational Psychology, 70(3), 337-351.

Martias, S. S. G. (2003). Peer acceptance of Children with Disabilities in Inclusive Preschool Programs: Predictors and Implications. University Of California.

Mikami, A. Y., Reuland, M. M., Griggs, M. S., \& Jia, M. (2013). Collateral Effects of a Peer Relationship Intervention 
for Children With Attention Deficit Hyperactivity Disorder on Typically Developing Classmates. School Psychology Review, 42(4), 458-476.

Morton, J. F., \& Campbell, J. M. (2007). Information source affects peers ' initial attitudes toward autism. Research in Developmental Disabiliities, 29(2008), 189-201. https://doi.org/10.1016/1.ridd.2007.02.006

Nevill, R. E. A., \& White, S. W. (2011). College Students ' Openness Toward Autism Spectrum Disorders: Improving Peer acceptance. Journal Autism Development Disorder, 41(2011), 1619-1628. https://doi.org/10.1007/s10803-011-1189-x

Pace, J. E., Shin, M., \& Rasmussen, S. A. (2010). Understanding attitudes toward people with down syndrome. Public Health Resources, 152(9), 2185-2192. https://doi.org/10.1002/ajmg.a.33595

Pelham, W. E., \& Milich, R. (1984). Peer Relations in Children with Hyperactivity/Attention Deficit Disorder. Journal of Learning Disabilities, 17(9), 560-567. https://doi.org/10.1177/002221948401700911

Piercy, M., Wilton, K., \& Townsend, M. (2002). Promoting the Social Acceptance of Young Children With Moderate - Severe Intellectual Disabilities Using Cooperative-Learning Techniques. Journal of Mental Retardationn, 107(5), 352-360.

Pinto, C., Baines, E., \& Bakopoulou, I. (2018). The peer relations of pupils with special educational needs in mainstream primary schools: The importance of meaningful contact and interaction with peers. British Journal of Educational Psychology, 89(1/2). https://doi.org/10.1111/bjep.12262

Putnam, J., Markovchick, K., Johnson, D. W., \& Johnson, R. T. (1996). Cooperative Learning and Peer acceptance of Students with Learning Disabilities. The Journal of Social Psychology, 136(6), 741-752.

Ranson, N. J., \& Byrne, M. K. (2014). Promoting Peer acceptance of Females with Higher-functioning Autism in a Mainstream Education Setting: A Replication and Extension of the Effects of an Autism Anti-Stigma Program. Journal Autism Development Disordes, 2014(44), 2778-2796. https://doi.org/10.1007/s10803-014-2139-1

Rillotta, F., \& Nettelbeck, T. E. D. (2007). Effects of an awareness program on attitudes of students without an intellectual disability towards persons with an intellectual disability. Journal of Intellectual \& Developmental Disability, 32(March), 19-27. https://doi.org/10.1080/13668250701194042

Robinson, M. J. (2004). Factors Affecting Peer acceptance of Children with Disabilities in Regular Schools. University of Tasmania.

Staniland, J. J., \& Byrne, M. K. (2013). The Effects of a Multi-Component Higher-Functioning Autism Anti-Stigma Program on Adolescent Boys. Journal Autism Development Disorder, (Attwood 2006). https://doi.org/10.1007/s10803-013-1829-4

Stanovich, P. J., Jordan, A., \& Perot, J. (1998). Relative differences in academic self-concept and peer acceptance among students in inclusive classroom. Remedial and Special Education, 19(2), 120-126.

Sue, W., \& Berthelsen, D. (2008). CHILDREN WITH AUTISTIC SPECTRUM DISORDER IN EARLY CHILDHOOD EDUC. International Journal of Early Childhood, 40(1), 33-51.

Weyns, T., Colpin, H., Laet, S. De, Engels, M., \& Verschueren, K. (2018). Teacher Support , Peer acceptance , and Engagement in the Classroom: A Three-Wave Longitudinal Study in Late Childhood. Journal of Youth and Adolescence, 47(6), 1139-1150. https://doi.org/10.1007/s10964-017-0774-5

Williamson, C. (2014). Effects of Disability Awareness Educational Programs on an Inclusive Classroom. Honors Projects, 134, 1-32. 